\title{
The Role of Low Blood Glucose Level of Mothers with Severe Preeclampsia in Fetal Growth Restriction: a Mini-Study
}

Authors:
Asri Prameswari
Department of Internal Medicine, Faculty of Medicine Universitas Brawijaya
Editor:
Lestariningsih

Received 21 December 2018, revised 8 March 2019, accepted 26 March 2019, published 1 April 2019

\begin{abstract}
Background. The number of patients with severe preeclampsia continues to increase worldwide. Blood glucose is significantly decreased in severe preeclampsia patients, starting at the sudden onset of high blood pressure. This depicts the state of low placental energy status in preeclampsia patients with intrauterine growth restriction (IUGR), due to either glycolysis or ischemia disorders resulting from decreased maternal placental blood flow.
\end{abstract}

Aim. To observe the relationship between mother's random blood glucose level with fetal growth restriction complications during acute onset of severe preeclampsia.

Methods. A cross-sectional study, random sampling involving twenty-one pregnant women with severe preeclampsia who underwent cesarean section at Permata Bunda Hospital, Malang, Indonesia. Data were taken from medical records, which included: mother's random blood glucose, blood pressure, proteinuria, and complete blood count. Fetal data includes body weight and length. The data were obtained at the subjects' initial admission in the emergency room during the acute phase of the preeclampsia.

Result. Maternal blood glucose had a negative and significant relationship with systolic blood pressure $(r=-0.843$, $\mathrm{p}<0.0001)$ and with newborn body weight $(\mathrm{r}=0.465, \mathrm{p}=$ $0.034)$ in the acute onset of severe preeclampsia.
Conclusion. The blood glucose level of patients at the acute onset of preeclampsia is inversely correlated with systolic blood pressure. The blood glucose level is also correlated with fetal weight. However, due to the chronic nature of IUGR, future studies should analyze the relationship between blood glucose, blood pressure, and fetal growth through multiple stages of pregnancy.

\section{Corresponding author:}

Asri Prameswari. Department of Internal Medicine Universitas Brawijaya.e-mail: asriprameswari@gmail.com

\section{Background}

Preeclampsia is defined as persistently high blood pressure that occurs after 20 weeks of pregnancy and is associated with the presence of protein in the urine or the new onset of decreasing blood platelet, kidneys or liver impairment, fluid in the lungs, signs of brain disorders such as seizures, and/or visual disturbances. ${ }^{1}$ Preeclampsia is a major cause of maternal and perinatal morbidity and mortality, with an estimated 50,000-60,000 deaths-related cases of preeclampsia per year worldwide. ${ }^{2,3}$ Severe preeclampsia can lead to acute and chronic complications in both the mother and the newborn, resulting from insufficiency of uteroplacental blood flow at preterm, birth, or both..$^{4-7}$ Fetal growth restriction is treated the same as pregnant women with or without pre- 
eclampsia, where procedures and surgery are performed as indicated by severe preeclampsia. ${ }^{8,9}$

Previous research on preeclampsia showed low placental energy status either due to impaired glycolysis, ischemia caused by decreased maternal placental blood flow, or both, and is responsible for fetal growth restriction. ${ }^{10}$ The presence of these abnormalities causes significant metabolic abnormalities in the placenta of pregnant women who experience severe preeclampsia and are thought to contribute to disturbances of other metabolic functions, including metabolic functions of blood glucose, lipid, and protein. ${ }^{11}$ Therefore, this study aim is to know the random blood glucose levels in pregnant women with severe preeclampsia at the acute onset of high blood pressure in the emergency room, and its relationship with systolic blood pressure and fetal growth restriction.

\section{Methods}

A cross-sectional study involving twenty-one pregnant women with severe preeclampsia who underwent cesarean section at Permata Bunda Hospital, Malang, Indonesia for 3 months (December 2017 to February 2018). Subjects were selected through random sampling. Data were taken from subjects' medical records, which included: blood glucose, blood pressure (systolic and diastolic), proteinuria, complete blood count (hemoglobin, leukocytes, and platelets), and the newborn anthropometric data (weight and length). Subjects were either admitted due to acute conditions or referred from primary healthcare. Data was presented in the form of mean and standard deviations. Data were analyzed to determine the relationship with the Pearson test after normality test conducted.

\section{Results}

This study showed random blood glucose has a negative and significant relationship with systolic blood pressure in women with acute onset of severe preeclampsia $(r=-0.843, p<$ $0.001)$ and has a relationship with the weight of newborn ( $\mathrm{r}$ $=0.465, \mathrm{p}=0.034)($ Table 1$)$.

This study showed random blood glucose has a negative and 26 significant relationship with systolic blood pressure in women with acute onset of severe preeclampsia $(r=-0.843, p<$ $0.001)$ and has a relationship with the weight of newborn ( $\mathrm{r}$ $=0.465, \mathrm{p}=0.034)$. (Table 2$)$

\section{Table 1. Characteristics of Patients}

\begin{tabular}{lc}
\hline \multicolumn{1}{c}{ Patient's Characteristics } & Mean + SD \\
\hline Age (years) & $31.9 \pm 6.43$ \\
Systolic Blood Pressure $(\mathrm{mmHg})$ & $162 \pm 11$ \\
Diastolic Blood Pressure $(\mathrm{mmHg})$ & $99 \pm 9$ \\
Haemoglobin $(\mathrm{g} / \mathrm{dl})$ & $11.57 \pm 1.3$ \\
Leukocyte $(\mu / \mathrm{L})$ & $12.676 \pm 3675$ \\
Trombocyte $(/ \mu)$ & $266,952 \pm 59,310$ \\
Random Blood Glucose $(\mathrm{mg} / \mathrm{dL})$ & $89 \pm 16$ \\
Neonatus Weight $(\mathrm{gr})$ & $2904.76 \pm 660.85$ \\
Neonatus Length $(\mathrm{cm})$ & $48.81 \pm 2.84$ \\
\hline
\end{tabular}

Table 2. Pearson's test

\begin{tabular}{clcc}
\hline Variable & \multicolumn{1}{c}{ Test } & $\begin{array}{c}\text { Systolic } \\
\text { Blood } \\
\text { Pressure }\end{array}$ & Newborn Weight \\
\hline \multirow{2}{*}{$\begin{array}{c}\text { Random Blood } \\
\text { Glucose }\end{array}$} & $\begin{array}{l}\text { Pearson's } \\
\text { Correlation }\end{array}$ & -0.843 & 0.465 \\
& Sig. (2-tailed) & 0.000 & 0.034 \\
& $\mathrm{~N}$ & 21 & 21 \\
\hline
\end{tabular}

\section{Discussion}

Results showed a low tendency of blood glucose in women with severe preeclampsia and IUGR, at the acute onset of high blood pressure. This might be due to low placental energy status caused by glycolysis, or the presence of ischemia in placental blood flow resulting from a decrease in maternal placental blood flow. Some highly coordinated metabolic adaptation mechanisms allow mothers to provide intermittent nutrition to supply not only for their own energy needs but also for fetal development. During this process, progressive insulin resistance and hyperinsulinemia appear as compensation for increasing nutrient storage in maternal fat and serve as a "shunt" of nutrients to the fetus by slowing down the absorption of nutrients into the mother's tissues, especially during late pregnancy. During this feeding process, the hormone released by the fetoplacental creates a progressive environment that supports catabolism of maternal fat as an energy substrate, thereby inhibiting InaKidney | Vol. II | Is. 1| Jan - Apr 2019 


\section{Prameswari A}

maternal protein catabolism along with carbohydrate for the fetus. Women without preexisting diabetes are able to develop glucose intolerance during late pregnancy if pancreatic beta cells are unable to compensate for insulin resistance and/or insulin resistance in normal pregnancy. ${ }^{9}$

In another research, the concentrations of pyruvate and lactate are significantly lower in the maternal placenta with severe preeclampsia, supporting the previous assumption about indirect glycolysis inhibition. However, direct measurements of nucleotide adenine concentrations do not indicate a decreased level of placental energy in patients with preeclampsia. Along with the absence of changes in lactate or pyruvate concentration, supports evidence against the hypothesis of placental ischemia that causes energy deficiency. Glycolysis is an important source of precursors, especially pyruvate, for the synthesis of amino acids and lipids, the results of this metabolism causing metabolic abnormalities in the patient's placenta with severe preeclampsia. ${ }^{10}$

Another previous study test the glucose tolerance in primigravida women with preeclampsia in the absence of preexisting diabetes showed that patients with severe preeclampsia had significantly lower fasting blood glucose levels compared to patients with normal pregnancy and patients with mild preeclampsia. Fasting Human Placental Lactogen / HPL levels were significantly lower in patients with severe preeclampsia compared with patients with normal pregnancy and mild preeclampsia. In addition, fasting plasma insulin and insulin response after glucose injection were lower in patients with severe preeclampsia, but not statistically significant. ${ }^{11,12}$

This study's results showed a low blood glucose tendency in severe preeclampsia patients with an acute onset of high blood pressure, where there were other studies showing a suspected decrease in carbohydrate metabolism in patients with severe preeclampsia to the same extent as patients with gestational diabetes, and presumably this metabolism decrease is due to maternal placental cell anoxia caused by vascular changes in patients with severe preeclampsia. ${ }^{11,12}$ Severe preeclampsia is associated with increased cerebral blood flow and perfusion pressure, especially during the postpartum period, but this association is less likely to cause significant changes in cerebral glucose metabolism. ${ }^{12,13}$
Normal pregnancy is characterized by low fasting blood glucose, higher postprandial blood glucose levels, and hyperinsulinemia. In studies using oral glucose intake, pregnant women showed hyperglycemia and hyperinsulinemia simultaneously with glucagon suppression. This cannot be explained by decreased insulin metabolism because its half-life during pregnancy does not change. Instead, this response is consistent with peripheral insulin resistance associated with pregnancy, the aim of this mechanism is to ensure the availability of postprandial glucose for the fetus. ${ }^{14,15}$

This study shows the association between the onset of high blood pressure and the newborn's weight, consistent with current evidence that severe preeclampsia is associated with significant fetal growth restriction. Women with a history of preeclampsia have a higher risk of having a baby who is less than gestational age. Preeclampsia is independently associated with the development of small infants in the uterus (Intra Uterine Growth Restriction / IUGR). While other studies have shown, women with chronic hypertension are not associated with IUGR, it is suspected that there is a difference in the mechanism of IUGR in women with hypertension superimposed with preeclampsia compared to preeclampsia alone. ${ }^{16}$

\section{Conclusion}

Random blood glucose in severe preeclampsia patients with fetal growth restriction complications is associated with systolic blood pressure and newborn's weight, especially at the acute onset of high blood pressure. However, the presence of IUGR is a result of chronic insult to the fetus. Therefore, the causal relationship between low blood glucose and IUGR needs to be further elucidated with a different type of study such as prospective cohort, to look for the relationship between pregnant patients' blood glucose, blood pressure, and fetal growth. A larger number of sample is also needed to determine the tendency of low blood glucose levels in patients with severe preeclampsia, and further studies are needed on the pathophysiology of glucose metabolism in patients with severe preeclampsia. 


\section{Reference}

1. Task Force on Hypertension in Pregnancy. Hypertension in pregnancy: Report of the American College of Obstetricians and Gynecologists' Task Force on Hypertension in Pregnancy. American College of Obstetricians and Gynecologist: Washington DC; 2013.

2. Jeyabalan A. Epidemiology of Preeclampsia: Impact of Obesity. Nutr Rev. 2013:71 Suppl 1(0 1); S18-25.

3. Osungbade KO, Ige OK. Public Health Perspectives of Preeclampsia in Developing Countries: Implication for Health System Strengthening. J Pregnancy. 2011:2011;481095.

4. Nankali, A, Malek-Khosravi Sh, Zangeneh M, Rezaei M., Hemati Z, Kohzadi, M. Maternal Complications Associated with Severe Preeclampsia. J Obstet Gynaecol India.2013 Apr:63(2);112-5.

5. Yücesoy G, Özkan S, Bodur H, Tan T, Caliskan E, Vural B, Coracki A. Maternal and Perinatal Outcome in Pregnancies Complicated with Hypertensive Disorder of Pregnancy: a Seven Year Experience of a Tertiary Care Center. Arch Gynecol Obstet. 2005 Nov;273(1):43-9.

6. Leeman L, Dresang LT, Fontaine P. Hypertensive Disorder of Pregnancy. Am Fam Physician. 2016 Jan 15; 93(2):121-7.

7. Lambert G, Brichant JF, Hartstein G, Bonhomme V, Dewandre PY. Preeclampsia: an Update. Acta Anaesthesiol Belg. 2014; 65(4):137-49.

8. Peres, G. M., Mariana, M., \& Cairrão, E., 2018. Preeclampsia and Eclampsia: An Update on the Pharmacological Treatment Applied in Portugal. J Cardiovasc Dev Dis. 2018 Jan 17;5(1)

9. Publications Committee Society for Maternal-Fetal Medicine, Sibai BM. Evaluation and Management of Severe Preeclampsia Before 34 Weeks' Gestation. Am J Obstet Gynecol. 2011 Sep;205(3):191-8.

10. Buchanan TA. Glucose Metabolism During Pregnancy: Normal Physiology and Implications for Diabetes Mellitus. Isr J Med Sci. 1991 AugSep;27(8-9):432-41.

11. Choi SJ, Lee JE, Oh SY, Kim GM, Cho YS, Lee $\mathrm{KH}$, et al. Maternal Cerebral Blood Flow and Glucose Metabolism in Pregnancies Complicated by Severe Preeclampsia. Hypertens Pregnancy. 2012;31(1):177-88.

12. Hauth J, Clifton R, Roberts J, Myatt L, Spong C, Leveno $\mathrm{K}$, et al. Maternal Insulin Resistance and
Preeclampsia. Am J Obstet Gynecol. 2011 Apr; 204(4): 327.e1-327.e6.

13. Sinha S, Singh GP, Gupta K, Kumar S, Gupta A. Effect of Preeclampsia on Insulin Sensitivity. Int J Appl Basic Med Res. 2014 Jan-Jun; 4(1): 7-10.

14. Salamalekis E, Vitoratos N, Makrakis E, Mastorakos G, Eleftheriadis M, Creatsas G. No Association Between Insulin Resistance and Preeclampsia. J Matern Fetal Neonatal Med. 2005 Aug; 18(2):1135.

15. Odegard RA, Vatten LJ, Nilsen ST, Salvesen KA, Austgulen R. Preeclampsia and Fetal Growth. Obstet Gynecol. 2000 Dec;96(6):950-5.

16. Srinivas SK, Eldow AG, Neff PM, Sammel MD, Andrela CM, Elovitz MA. Rethinking IUGR in Preeclampsia: Dependent or Independent of Maternal Hypertension?. J Perinatol. 2009 Oct;29(10):680-4. 